\title{
Views of Secondary Education Teachers in Cyprus, Regarding the Information They Receive for Pupils with Chronic Diseases in Their Classes
}

\author{
Stavrou Stavros, Demetriou Loucia* \\ School of Education and Social Sciences, Frederick University, Limassol, Cyprus \\ E-mail: pre.dl@frederick.ac.cy
}

Received: 13 March 2021; Revised: 9 April 2021; Accepted: 26 April 2021

\begin{abstract}
In Cyprus, many pupils with chronic diseases attend public school in regular classes, managing their disease's demands in parallel with their education. Teachers are responsible for both education and management of these pupils at school. They have to see to their safety, but they must also provide equal learning opportunities to pupils with chronic diseases. Therefore, teachers' information about each child's condition and needs is crucial for their better response to the challenge of coping with the unique needs these pupils may have at school and in the classroom. This study's purpose is an initial investigation of the quality of the information teachers receive in this context. Our methodology is qualitative. We conducted twelve interviews with secondary education teachers in Larnaca and Famagusta in Cyprus during 2019-2020. We analyzed our data by applying the Thematic Content Analysis method. Our findings indicated that teachers felt that the school's information regarding pupils with chronic diseases was either incomplete or, even worse, non-existent.
\end{abstract}

Keywords: chronic diseases, teachers, information, school counselor, parents

\section{Introduction}

The management of chronic diseases is a significant challenge globally, and it is now a priority issue for the World Health Organization (WHO). According to WHO (2015), chronic diseases cause more than $70 \%$ of deaths worldwide each year, with the rate increasing rapidly, while the cost to health systems is already unbearable. Chronic diseases are defined broadly as conditions that last one year or more and require ongoing medical attention or limit activities of daily living or both or are defined as such from the time of diagnosis (CDC, 2021).

Many pupils and adolescents suffer from a chronic disease, which causes both difficulties in their daily lives and at school, leading to special physical and psychological needs; consequently, millions of pupils and their families are living under significant stress (Beachman \& Deatrick, 2015; McQuoid, 2017; Bartchel et al., 2018). As far as school is concerned, pupils and adolescents with chronic diseases have problems such as frequent absences (Crump et al., 2013), school performance (Lum et al., 2017), and interpersonal relationships (Mackner et al., 2012), while age and puberty seem to be significant factors when living with a chronic disease (Van Staa, 2012; Gorter, et al., 2014; Ferro, 2014).

Teachers are called upon to manage such issues in the general classroom. Even though they lack relevant formal

Copyright (C2021 Demetriou Loucia, et al.

DOI: https://doi.org/10.37256/ser.222021827

This is an open-access article distributed under a CC BY license

(Creative Commons Attribution 4.0 International License)

https://creativecommons.org/licenses/by/4.0/ 
training, they still have to bear the responsibility for the pupils' safety and education. According to research, although the number of pupils with chronic diseases in schools is on the rise, frontline teachers are not receiving the required training and are not prepared to meet this challenge to the required degree (Nurmi \& Stieber-Roger 2012; Selekman, 2016; Stavrou \& Demetriou, 2019).

However, apart from any formal training, an essential factor for the ability of teachers to cope is the information exchange, both about chronic diseases in general but mostly about pupils with chronic diseases in their classes; pupils with whom they come into contact for many hours every day at both academic and personal level. The primary source of such information is the parents of pupils with chronic diseases themselves but also the school counselor, together with various experts responsible for supporting these pupils and training the teachers, especially in schools where a school nurse is not an option, and the responsibility lies on the school stuff (Hanley Nadeau \& Toronto, 2016).

According to the Career Counselling and Education Services (2021) of the Cyprus Ministry of Education, Culture, Sports, and Youth, the school counselor is responsible for receiving all personal and family data for the pupil, and this information is initially collected from the parents/guardians as well as from interviews conducted with any new students. Then they inform the teachers about any issues that concern their students during special meetings called pedagogical sessions, conducted in a climate of confidentiality.

It is therefore clear that the role of the school counselor is crucial, both for pupils and their teachers, since he/she is the contact between school and the family and the person to communicate the information so that teachers and other school staff will be aware of the situation and the plan to accommodate the pupils in the classroom or support them in case of problems (Hamlet, Gergar \& Schaefer, 2011; Hamlet \& Herrick, 2011; Warren \& Baker, 2013). It means that teachers and school counselors' collaboration can make a difference when it comes to pupils with special needs in the school setting and as Kourkoutas and Giovazolas (2015) suggest, teachers can indeed effectively assist students with difficulties or at risk at school if they are adequately guided and supported by well-trained school counselors.

Besides the school counselor, another critical role is the role of any specialists responsible for supporting both the pupils and the teachers, such as the School Psychology Service, Special Education, nurses or representatives, and members of expert associations that collaborate with the school. It is important to note here that only the school counselors can share critical personal information of the pupils with the teachers, and the rest of the abovementioned stakeholders have or must have a supportive role, such as training the teachers.

In this context, the purpose of our study is an exploratory approach to assess the quality of information that secondary school teachers in Cyprus receive regarding pupils with chronic diseases in their classes. We posed two research questions: (1) Where do teachers receive information from about pupils with chronic diseases in their classroom? (2) What is the quality of information they receive about pupils with chronic diseases in their classroom?

\section{Methodology}

Our methodology is qualitative, and we obtained our data by conducting semi-structured interviews with secondary school (high school) teachers. We chose this method because it reflects our belief that qualitative interviews allow an indepth exploration of teachers' knowledge, experience, and perception regarding the information they receive about their students suffering from chronic diseases.

\subsection{Sample}

Twelve frontline teachers of various specialties and experiences in public high schools in Cyprus participated in the survey. Their participation criteria were two: (a) to serve in a secondary public school in Cyprus and (b) to have come into contact with a child/adolescent with chronic disease in a general classroom. To recruit our subjects, we used announcements in three public high schools and the avalanche method. All participants were teaching in secondary schools in the districts of Larnaca and Famagusta during the period of the interviews. Participants T5, T7, T9, and T12 were teaching in a gymnasium, pupils age 12-14 years old and T1, T2, T3, T4, T6, T8, T10, and T11 were teaching in high school, pupils age 15-17 years old. All teacher data are presented in Table 1. 
Table 1. Teachers' profile and characteristics

\begin{tabular}{|c|c|c|c|c|c|}
\hline Code & Sex & Specialty & $\begin{array}{l}\text { Experience } \\
\text { (Years) }\end{array}$ & $\begin{array}{l}\text { Pupil with cd } \\
\text { in class }\end{array}$ & Type of disease/diseases \\
\hline $\mathrm{T} 1$ & $\mathrm{~F}$ & Physical education & 21 & Yes & Epilepsy, asthma, diabetes T1 \\
\hline $\mathrm{T} 2$ & $\mathrm{~F}$ & Biology & 20 & Yes & $\begin{array}{c}\text { Diabetes T1, heart disease, } \\
\text { ADHD, autism }\end{array}$ \\
\hline $\mathrm{T} 3$ & M & Physics & 20 & Yes & $\begin{array}{l}\text { Vision, hearing, epilepsy, } \\
\text { diabetes } \mathrm{T} 1 \text {, heart disease }\end{array}$ \\
\hline $\mathrm{T} 4$ & $\mathrm{~F}$ & Philology & 20 & Yes & $\begin{array}{l}\text { Diabetes T1, epilepsy, cancer, } \\
\text { asthma, heart disease }\end{array}$ \\
\hline T5 & M & Physical education & 20 & Yes & Diabetes T1, epilepsy, asthma \\
\hline T6 & $\mathrm{F}$ & Philology & 20 & Yes & Diabetes T1, epilepsy \\
\hline $\mathrm{T} 7$ & $\mathrm{~F}$ & Philology & 17 & Yes & $\begin{array}{l}\text { Epilepsy, heart disease, } \\
\text { diabetes T1 }\end{array}$ \\
\hline $\mathrm{T} 8$ & $\mathrm{~F}$ & Philology & 16 & Yes & Diabetes T1, epilepsy, cancer \\
\hline T9 & M & Languages & 16 & Yes & Diabetes T1, Crohn's (IBD) \\
\hline $\mathrm{T} 10$ & $\mathrm{~F}$ & Mathematics & 13 & Yes & $\begin{array}{l}\text { Diabetes T1, epilepsy, unknown } \\
\text { terminal chronic disease }\end{array}$ \\
\hline $\mathrm{T} 11$ & $\mathrm{~F}$ & Computer science & 11 & Yes & Epilepsy, diabetes T1 \\
\hline T12 & M & Philology & 8 & Yes & Vision, hearing, diabetes $\mathrm{T} 1$ \\
\hline
\end{tabular}

\subsection{Data collection and analysis}

We collected all data through semi-structured interviews conducted in a place selected by the participants. The semi-structured interview provides an opportunity to express personal opinions in length; data collection stopped when saturation occurred, and it became apparent that no new data would be added (Patton, 2002; Latham, 2013). Each interview was recorded, and transcripted word by word to maintain each participant's style and tone and each transcript was supported by field notes.

We carried out data analysis by applying the Thematic Content Analysis, which according to Bengtsson (2016), is an ideal method for subjects where opinions and experiences are studied. We present the two phases of the thematic analysis in Table 2.

Table 2. Phases of data analysis

\begin{tabular}{cc}
\hline Phase one & Phase two \\
\hline 1. Transliteration & 5. Grouping \\
2. Organization of data & 6. Repetition \\
3. Coding & 7. Transition \\
4. Repetition & \\
\hline
\end{tabular}

Following the processing of the data and the codification, three categories emerged concerning the teachers' sources of information about pupils with chronic diseases in their class. The first category is the school counselor. The second concerns the experts inside and outside the school unit, and the third concerns the parents of the pupils themselves. The categories are presented in Table 3, along with their labels. 
Table 3. Categories and labels

\begin{tabular}{cc}
\hline Category & Label \\
\hline $\begin{array}{c}\text { School counselor } \\
\text { Specialists }\end{array}$ & $\begin{array}{r}\text { Information and quality of information the teachers receive from school counselor } \\
\text { as regards the pupils with chronic diseases in their classroom. }\end{array}$ \\
Parents & $\begin{array}{c}\text { Information and quality of information the teachers receive from specialists inside } \\
\text { and outside the school as regards pupils with chronic diseases in their classroom. } \\
\text { Information and quality of information the teachers receive from the parents of } \\
\text { pupils with chronic diseases in their classroom }\end{array}$ \\
\hline
\end{tabular}

\section{Results}

\subsection{Category 1: Information from the school counselor}

According to the participating teachers, the school counselor provides information and updates to some extent, but this information does not always occur, does not reach everyone, and is not always substantial. The most common way the school counselor informs the teachers about pupils' health issues is during in-school pedagogical sessions, usually twice each school year. This established practice has two significant disadvantages, which seem to be critical for the pupils and the teachers: Firstly, each school in Cyprus, no matter how big, has one or two school counselors on duty each year. That means that it is impossible to coordinate everything on time. Secondly, each pedagogical session takes place after the school planning for the school year is complete and finalized so that each teacher knows his classes and students for the current school year. Therefore, since the school year usually begins in the first week of September, at least by the time the time the first session takes place, the school year is well on its way.

Consequently, often enough, crucial information regarding a pupil's health issues reaches the teacher relatively late in the school year. Moreover, pupils feel the need to inform their teachers themselves because of this delay, making them feel uncomfortable. A participant talks about that feeling referring to a child with diabetes:

The school counselor has informed me but, as you understand and as you know, the school counselor is usually late. The pedagogical session takes place in November-December. It's relatively late. I had X in my class, and he told me himself when he had to eat at some point because he wasn't feeling well. He told me, ma'am... His classmates knew it, but I didn't know it! (T4).

Sometimes the school counselor is not fully aware of the child's health condition, even in cases where the problem is severe and causes severe stress on the teacher. A participant cites a shocking case she experienced where the child finally passed away during the school year. In remembrance of the event, the teacher burst into tears, raising more concerns as regards the psychological support the teachers need in such cases:

It was a challenging situation because we had the ventilator all the time in the classroom, throughout the classes. She (the ill pupil) was under blankets to keep her body warm. She had terrible blood circulation; she had deformities in her face, an infection in her mouth, many dermatological issues, and a wheelchair [...].

The counselor did not know anything more to tell me. No one could tell me anything. (T10)

Several of our participants raised the issue of the quality of the information they received from the school counselor. A participant's statement allows us to make a significant observation: the quality of information is questionable even if a child's chronic disease is severe. The passage that follows refers to a child with a heart condition, where the information was very general and vague. Despite the seriousness of the disease, only some general instructions were given, without any form of training taking place:

The counselor just informed me about the problem; in fact, not so thoroughly. He just mentioned the problem.

We did not go into details. The truth is, we do not know anything. (T7)

The same situation is described by other participants, too, regarding epilepsy, cancers, diabetes, and asthma, for which the teacher was only given a printed sheet of paper with a small paragraph with some information. In other cases, the school counselor's information provided information during the pedagogical session that was just as inaccurate. For example, a participant who happens to have extensive knowledge and training in autism because she has a child with chronic illness in her family reported: 
Like many times we were officially informed in pedagogical sessions by the counselors about specific diseases, some of the things they were telling us were inaccuracies. They tried to be professionals, but there were many inaccuracies about the condition and how we can help. (T2)

\subsection{Category 2: Information from the specialists}

Another source of information for teachers is the specialists that work with schools, and they are usually psychologists, nurses or representatives, and members of expert associations. These experts may visit the school and speak informatively to individuals or groups or-in the case of the School for the Blind and School for the Deaf in Nicosia-some teachers may attend a seminar on these institutions' premises. It is worth mentioning that none of the participants mentioned any support from a psychologist, a doctor, or the School Psychology Service.

Teachers stated that the seminars organized by the institutions, as mentioned earlier, were of the highest quality and effectiveness regarding pupils with visual and hearing impairments. In particular, two teachers who attended training at this school reported that it was one of the best training they had ever received; they also reported that they learned several things that helped them manage pupils with such problems. A participant explains his experience at the School for the Deaf:

We did internships. I also spoke with students who graduated from the school, with hearing problems. It was indeed one of the best training I ever went to. (T12)

It seems that specialists' information is particularly beneficial for teachers, although those participants who received information from such specialists in a regular school did not share the same positive opinion about its quality and effectiveness. For example, a participant refers to her case, where specialists from the schools, as mentioned earlier, visited her school and provided information for a child with visual and one with hearing impairment:

For the vision impairment, somebody came at the beginning of the school year to inform us, and someone else

came for the hearing impairment. They just tell you a few things. It is nothing much. (T2)

In this case, the information was not as detailed and did not have the quality of the information provided in specially designed environments, where practical training is possible or where long and multifaceted training seminars take place. Similar reports by teachers regarding expert lectures or seminars at the school show that although experts deliver speeches, i.e., about diabetes, teachers still did not feel that they had acquired any essential knowledge, and if they had, the quality of such knowledge was low. Therefore, we can assume that the place and time are determining factors in the quality of these training. It seems that so far, such an opportunity is given only to a few:

Information came from an educational institution that is in Nicosia, the School of the Deaf. I went there; they sent me [to the school] for two days. That was the best thing that ever happened: everything I had to hear, I heard it there, tuned up for two whole days, from morning till noon, with experts, where you really understand that you know nothing. You do not get to become an expert, but you gain much understanding. (T3).

\subsection{Category 3: Information from parents}

Participants referred to the communication with the parents, exposing a situation where it seems that this channel is in many cases closed, while in others, it is significantly blocked at either side. For example, some parents of pupils with chronic diseases contact their child's educator but do not provide information about the disease or open a communication channel on this matter. The contact is more about the student's performance or behavior, two problems that neither side relates to the disease. For example, a participant says that parents never paid her a visit beyond the regular visit for the performance of the child, although in her career, she had pupils with chronic diseases in her class:

No parents happened to come to address that matter. I mean, besides the regular visit for the academic

performance of their child. OK, I didn't happen to be approached by a parent in order to tell me 'you know my child has this problem and...'. (T6)

In other cases, the parents inform the teachers, but only because they know them personally. As the participants explained, in any other case, they would not know of the problem. For this matter, it is worth mentioning the statement of a teacher who did not consider it necessary to know:

I was informed by the child's mom. I knew her, but I did not know her son was sick, and one day, while we were talking, she told me her son was ill. OK. I told her why I needed to know. She said she needed to let me 
know... (If I did not know her) I would not know. (T9)

A participant referred to situations when the parents or one of them contacts the educator not to inform him/her about the child's disease, but because of the child's delinquent behavior. Neither of them considered the possibility that the child's behavior related to his health problems, although the literature states that in many cases, there is a direct relationship between the two:

A child's father came because the child was delinquent. Not for information, for the disease, only because of

his responsibility for the child. Only because his child was having behavioral problems. (T8)

An interesting statement comes from an experienced teacher with a specialty in Physical Education, who says that parents want to hide the child's disease. Such parental behaviors occur more frequently when the child's ailment is associated with prejudice, e.g., in epilepsy and cases involving mental health.

In some cases, we see that there is a... let us say... the parents want to conceal it, they think that... they do not want to communicate it or... Yes, there is this thing, the prejudice. It exists. Some parents do not want to mention anything. (T5)

\section{Discussion}

Our research focused on an exploratory approach to the quality of the information the high school teachers receive about pupils with chronic diseases in their classroom. Regarding our research questions, we established the following: Our participating teachers received some form of information from the school counselor, from seminars given by specialists and the parents. However, this information did not always come through, and most of the time, the quality was low. Therefore, teachers did not feel ready or confident to respond to chronic diseases in school.

Our findings are in line with other researchers' findings globally as recent research confirms that teachers do not yet have any special knowledge about chronic diseases (Kise et al., 2017; Sole et al., 2017). The findings relate to the lack of information provided to them and the absence of educational programs designed for teachers to educate them on chronic diseases.

Participants claimed that the aspect of information within the school unit by the school counselor was neither adequate nor effective. The issue of information and education received by the counselor himself does not concern the present paper, but it seems that various factors block the mechanism. The most important of them seemed to be the counselor's difficulty coping with his complex role, as he/she undertakes multiple tasks in the school unit (Kounenou et al., 2010; Kovač et al., 2017; King et al., 2018). Research indicates the difficulty of cooperation between school counselors and teachers, stressing the need to inform and educate them, especially in demanding situations (Calvery \& Hyun, 2013; Kourkoutas \& Ganzolias, 2015; Dumitru, 2015).

One could assume that although the counselor's information was not the expected one, the information from specialists would be of higher quality. However, while this might occur, it was not always the case; educators also reported negative experiences. Other researchers came to the same conclusion, as they also pointed out that teachers did not always have the necessary support or training by specialists or when they did, this did not yield the expected results (European Commission, 2013; Zinsser et al., 2016; Norwani et al., 2018; Murano et al., 2019).

Previous research has sufficiently supported the importance of communication and close cooperation between the two parts regarding parents' information. In particular, teachers who have an open communication channel with parents understand adolescents and their needs better, manage to support them better, integrate them better and offer them a quality school experience (Kourkoutas et al., 2017). According to the participants, however, there was no sufficient information from parents or any form of quality support to teachers in pupils with chronic diseases. Findings showed an incomplete or complete lack of information from parents and a need for better communication (Ellis et al., 2015; Mautone et al., 2015; Snopek \& Moravcikova, 2017; Kraft, 2017).

\section{Conclusion}

The purpose of this qualitative research was a first exploratory approach to the issue of the quality of the 
information teachers receive in high school in Cyprus about pupils with chronic diseases in their classroom, a matter that is still understudied in Cyprus. Our findings are in line with the findings of other researchers globally and suggest that the matter of informing teachers and generally gaining knowledge about chronic diseases needs further investigation, by both qualitative and quantitative methods. Also, the school counselor's role, the specialists, and other stakeholders need further investigation, as their support can assist the frontline teacher in his work with pupils with chronic diseases in the regular classroom.

\section{Limitations}

Although generalization is not a factor of concern in qualitative research, it is a fact that the study was conducted in only two districts in Cyprus, with a small number of participants. Therefore, more research is needed in the specific area to assess the bigger picture and measure the complete aspects of the problem. Irrespective of the limitations, the findings provide the first look in an area still understudied in Cyprus and provides essential information for a population still invisible: The pupils with chronic diseases in mainstream schools in Cyprus.

\section{Acknowledgments}

The authors are grateful to the teachers who participated in this research.

\section{Conflict of interest}

The authors declare no conflict of interest.

\section{Authors' contribution}

Both authors contributed equally to the conception and writing of the manuscript.

\section{About the authors}

Stavros Stavrou is a high school teacher with an MA in Counseling and Career Development, currently pursuing a Ph.D. in Counseling at the School of Education at Frederick University.

Dr. Loucia Demetriou is an Associate Professor of Psychology and currently chairs the Department of Psychology and Social Sciences at Frederick University, Cyprus.

\section{References}

Barthel, D., Ravens-Sieberer, U., Nolte, S., Thyen, U., Klein, M., Walter, O., Meyrose, A., Rose, M., \& Otto, C. (2018). Predictors of health-related quality of life in chronically ill pupils and adolescents over time. Journal of Psychosomatic Research, 109, 63-70. https://doi.org/10.1016/j.jpsychores.2018.03.005

Beachman, B. L., \& Deatrick, J. A. (2015). Perspectives on condition management. Journal of Pediatric Nursing, 30 , 25-35.

Bengtsson, M. (2016). How to plan and perform a qualitative study using content analysis. Nursing Plus, 2, 8-14.

Career Counselling and Education Services. (2021). http://www.moec.gov.cy/ysea/ypiresies/2019_kathikonta_ kathigiton_sea.pdf

Calvery, S. V., $\&$ Hyun, J. H. (2013). Sustaining education through enhanced collaboration between teachers and school 
counsellors. Educational Research Journal, 28(1), 125-144.

CDC. (2021). About Chronic Diseases. About Chronic Diseases. https://www.cdc.gov/chronicdisease/about/index.htm

Crump, C., Rivera, D., London, R., Laudan, M., Erlendson, B., \& Rodriguez, E. (2013). Chronic health conditions and school performance among pupils and youth. Annals of Epidemiology, 23, 179-184.

Dumitru, G. (2015). Teacher's role as a counsellor. Social and Behavioral Sciences, 180, 1080-1085.

Ellis, M., Lock, G., \& Lummis, G. (2015). Parent-teacher interactions: Engaging with parents and carers. Australian Journal of Teacher Education, 40(5), 160-174. https://doi.org/10.14221/ajte.2015v40n5.9

European Commission. (2013). Supporting teacher educators. https://ec.europa.eu/assets/eac/education/policy/school/ doc/support-teachereducators_en.pdf.

Ferro, M. A. (2014). Adolescents and young adults with physical illness: A comparative study of psychological distress. Acta Paediatrica, 103, 32-37.

Gorter, J. W., Steward, D., Woodbury, S. M., King, G., Nguyen, T., \& Swinton, M. (2014). Pathways toward positive psychosocial outcomes and mental health for young with disabilities: A knowledge synthesis of development trajectories. Acta Paediatrica, 103(1), 32-37.

Hamlet, H. S., Gergar, P. G., \& Schaefer, B. A. (2011). Students living with chronic illness: The school counselor's role. Professional School Counseling, 14(3), 2156759X1101400. https://doi.org/10.1177/2156759x1101400304

Hamlet, H. S., \& Herrick, M. A. (2011). Who's on first?: Professional collaboration and pupils with chronic illness. Vistas. https://www.counseling.org/knowledge-center/vistas/by-year2/vistas-2011/docs/default-source/vistas/ vistas_2011_article_82

Hanley Nadeau, E., \& Toronto, C. E. (2016). Barriers to asthma management for school nurses. The Journal of School Nursing, 32(2), 86-98. https://doi.org/10.1177/1059840515621607

King, C., Subotic-Kerry, M., \& O'Dea, B. (2018). An exploration of the factors associated with burnout among NSW secondary school counsellors. Journal of Psychologists and Counsellors in Schools, 28(2), 131-142. https://doi. org/10.1017/jgc.2018.5

Kise, S. S., Hopkins, A., \& Burke, S. (2017). Improving school experiences for adolescents with type 1 diabetes. Journal of School Health, 87(5), 363-375. https://doi.org/10.1111/josh.12507

Kounenou, K., Koumoundourou, G., \& makri-Botsari, E. (2010). Greek school career counselors competencies and burnout syndrome. Social and Behavioral Sciences, 2, 1890-1895.

Kourkoutas, E., \& Giovazolias, T. (2015). School-based counselling work with teachers: An integrative model. The European Journal of Counselling Psychology, 3(2), 137-158. https://doi.org/10.5964/ejcop.v3i2.58

Kourkoutas, E., Stavrou, P. D., \& Loizidou, N. (2017). Exploring teachers' views on including pupils with special needs in Greece: Implication for inclusive counselling. American Journal of Educational Research, 5(2), 124-130.

Kovač, J., Krečič, M. J., Čagran, B., \& Mulej, M. (2017). Effect of supervision on stress and burnout in school counsellors: A case of action research. Systemic Practice and Action Research, 30(4), 395-406. https://doi. org/10.1007/s11213-016-9400-9

Kraft, M. A. (2017). Engaging parents as partners in education through better communication. Educational Leadership, $75(1), 58-62$.

Latham, J. R. (2013). A framework for leading the transformation to performance excellence part II: CEO perspectives on leadership behaviors, individual leader characteristics, and organizational culture. Quality Management Journal, 20(3), 19-40. https://doi.org/10.1080/10686967.2013.11918354

Lum, A., Wakefield, C. E., Donnan, B., Burns, M. A., Fardell, J. E., \& Marshall, G. M. (2017). Understanding the school experiences of pupils and adolescents with serious chronic illness: A systematic meta-review. Child: Care, Health and Development, 43(5), 645-662. https://doi.org/10.1111/cch.12475

Mackner, L. M., Bickmeier, R. M., \& Crandall, W. V. (2012). Academic achievement, attendance, and school-related quality of life in pediatric inflammatory bowel disease. Journal of Developmental \& Behavioral Pediatrics, 33(2), 106-111. https://doi.org/10.1097/dbp.0b013e318240cf68

Mautone, J. A., Marcelle, E., Tresco, K. E., \& Power, T. J. (2015). Assessing the quality of parent-teacher relationships for students with adhd. Psychology in the Schools, 52(2), 196-207. https://doi.org/10.1002/pits.21817

McQuoid, J. (2017). Finding joy in poor health: The leisure-scapes of chronic illness. Social Science and Medicine, $183,88-96$.

Murano, D., Way, J. D., Martin, J. E., Walton, K. E., Anguiano-Carrasco, C., \& Burrus, J. (2019). The need for highquality pre-service and in-service teacher training in social and emotional learning. Journal of Research in Innovative Teaching \& Learning, 12(2), 111-113. https://doi.org/10.1108/jrit-02-2019-0028

Norwani, N. M., Daud, W. M., Mansor, M., \& Yusof, R. (2018). The relationship between in-service training and 
teaching skills with student achievement. International Journal of Academic Research in Business and Social Sciences, 7(12), 61-76. https://doi.org/10.6007/ijarbss/v7-i12/3593

Nurmi, M. A., \& Stieber-Roger, K. (2012). Parenting pupils living with type1 diabetes: a qualitative study. The Diabetes Educator, 38, 530-536.

Patton, A. (2002). Qualitative Rsearch and Evaluation Methods. Sage Publications Inc.

Selekman, J. (2016). Students with chronic conditions: Experiences and challenges of regular education teachers. The Journal of School Nursing, 33(4), 307-315. https://doi.org/10.1177/1059840516674053

Snopek, P., \& Moravcikova, D. (2017). Evaluation of the project "From novice teacher to teacher mentor"-Teacher's work with the chronically ill pupils. Procedia-Social and Behavioral Sciences, 237, 745-750. https://doi. org/10.1016/j.sbspro.2017.02.116

Solé, E., Castarlenas, E., Sánchez-Rodríguez, E., Galán, S., De la Vega, R., Jensen, M. P., \& Miró, J. (2017). Chronic pain in the school setting: The teachers' point of view. Journal of School Health, 88(1), 65-73. https://doi. org/10.1111/josh.12582

Stavrou, S., \& Demetriou, L. (2019). Secondary Education teachers' perceptions and knowledge for epilepsy in Cyprus and the ethical aspect of the matter. Hellenic Society of Counseling and Guidance Journal, 116-117, 92-101.

van Staa, A. L. (2012). On your own feet: Adolescents with chronic conditions and their preference and competence for care [Doctoral dissertation].

Warren, J. M., \& Baker, S. B. (2013). School counsellor consultation: Enhancing teacher performance through rational emotive-social behavioral consultation. Vistas Online. https://www.counseling.org/docs/default-source/vistas/ school-counselor-consultation-enhancing-teacher-performance.pdf?sfvrsn=2debf64c_11

WHO. (2015). Assessing national capacity for the prevention and control of noncommunicable diseases: Report of the 2015 global survey. WHO: Geneva.

Zinsser, K. M., Christensen, C. G., \& Torres, L. (2016). She's supporting them; who's supporting her? Preschool centerlevel social-emotional supports and teacher well-being. Journal of School Psychology, 59, 55-66. https://doi. org/10.1016/j.jsp.2016.09.001 